S6A Fig.

Proposed structures corresponding to spectrum shown in Fig. 6A

+FTMS ${ }^{2}$ m/z 771.6, PC 34:2(+[2]H13)

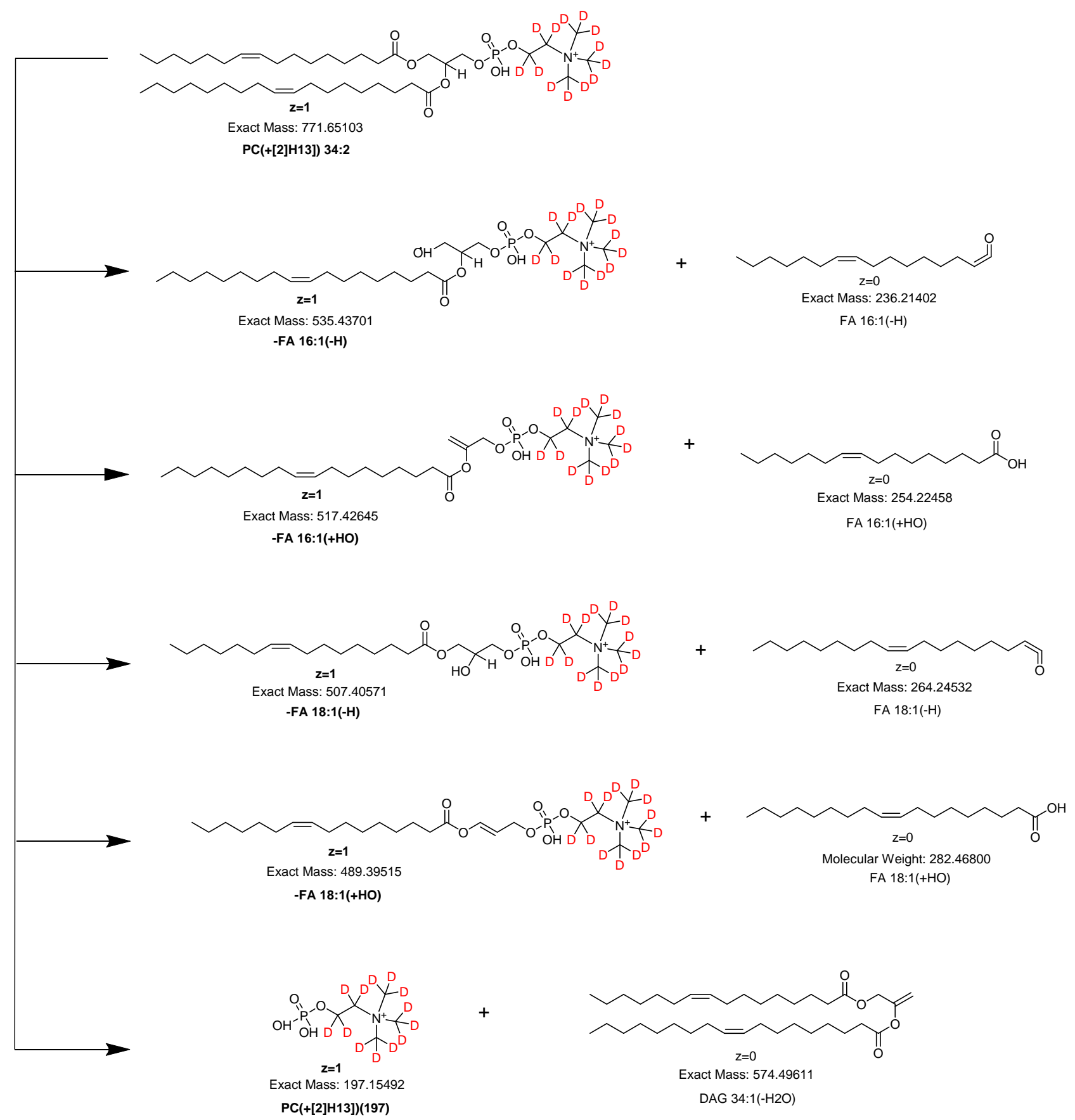




\section{S6B Fig.}

Proposed structures corresponding to spectrum shown in Fig. 6B.

+ FTMS $^{2} m / z$ 740.6, PC 32:0(+[2]H6)

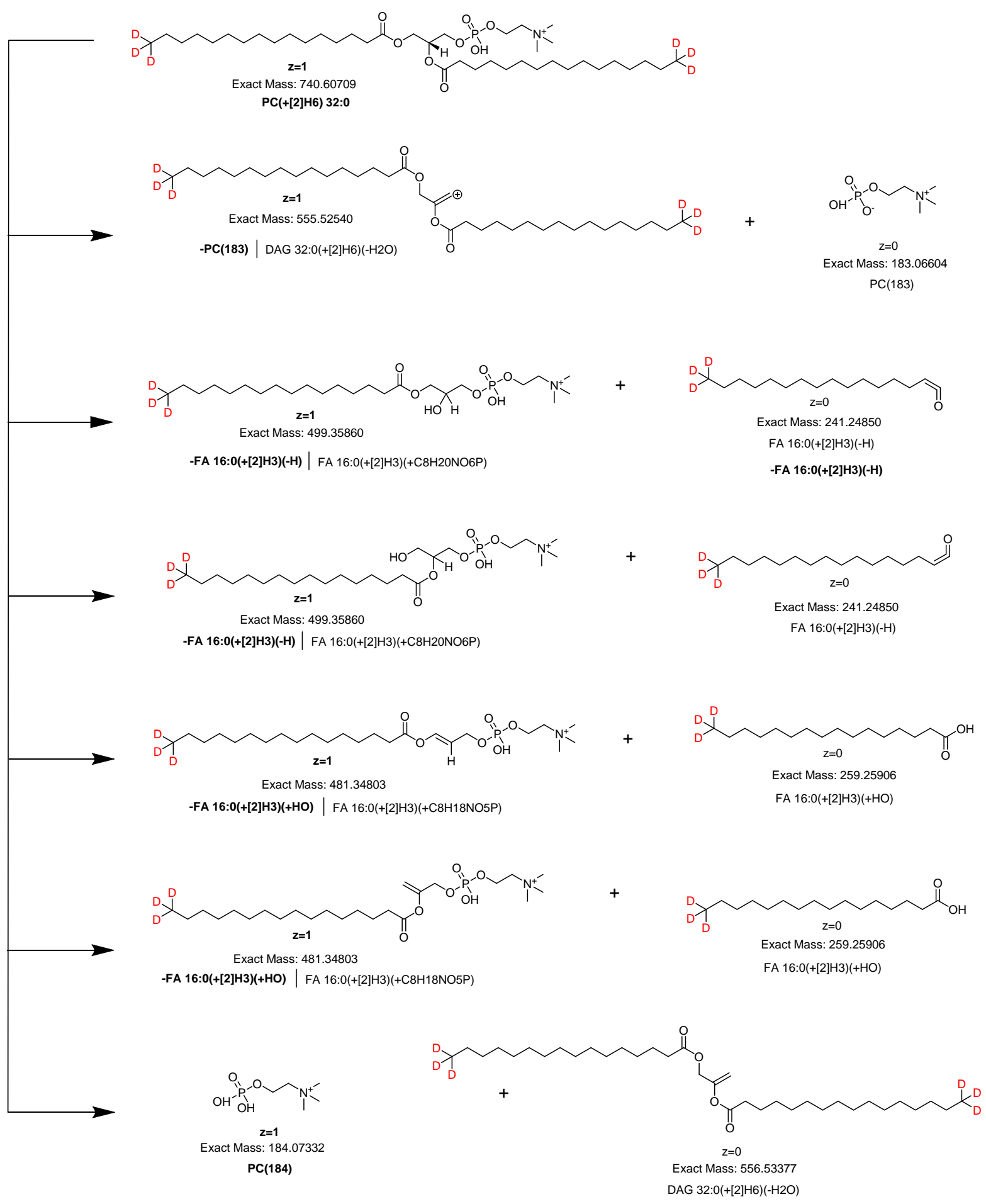




\section{S6C Fig.}

Proposed structures corresponding to spectrum shown in Fig. 6C.

-FTMS ${ }^{2}$ m/z 841.6, PI 34:1(+[2]H6)

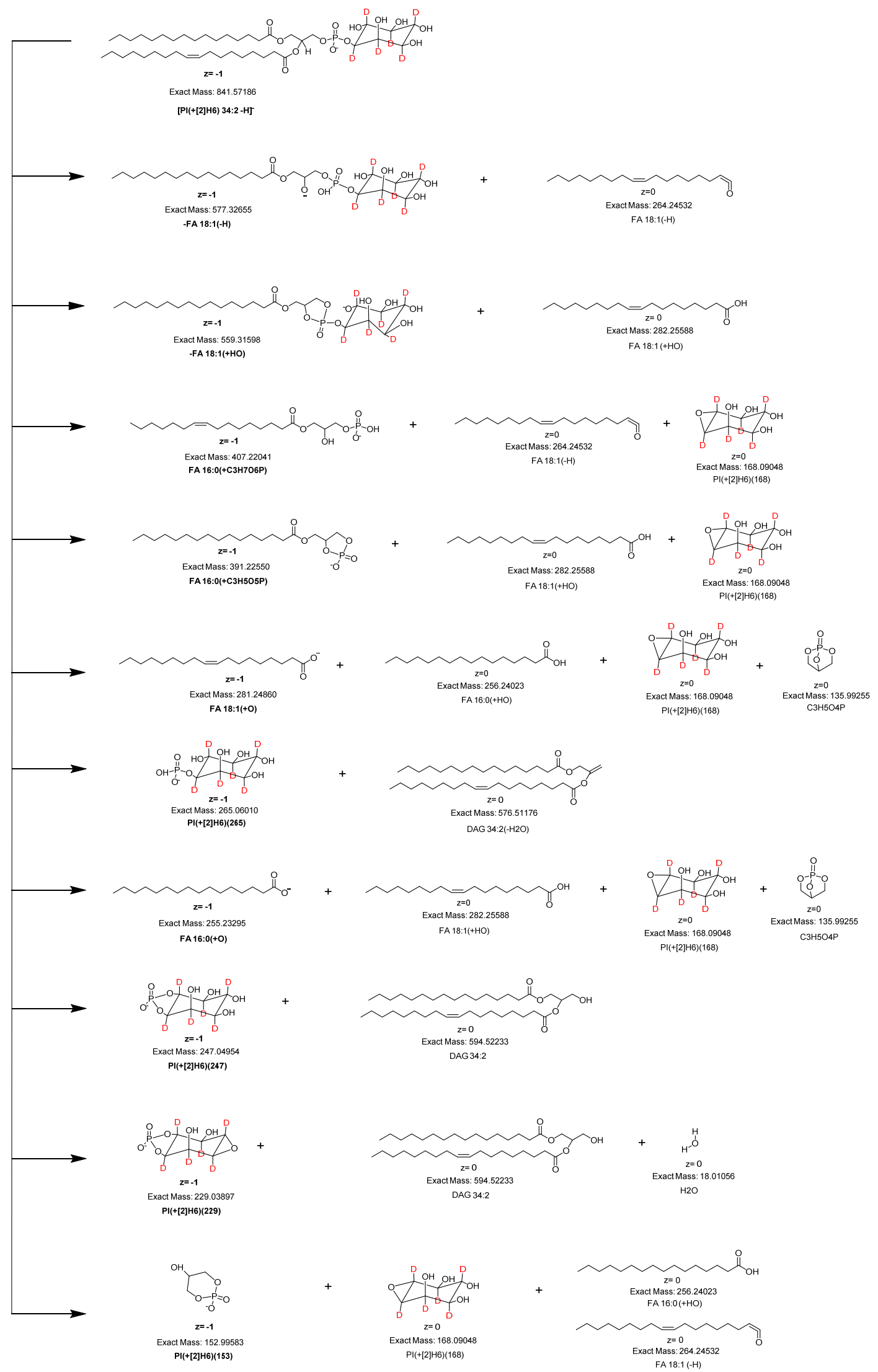


S6D Fig.

Proposed structures corresponding to spectrum shown in Fig. 6D.

- FTMS $^{2}$ m/z 759.7, Cer 44:0;4(+[13]C2[15]N)

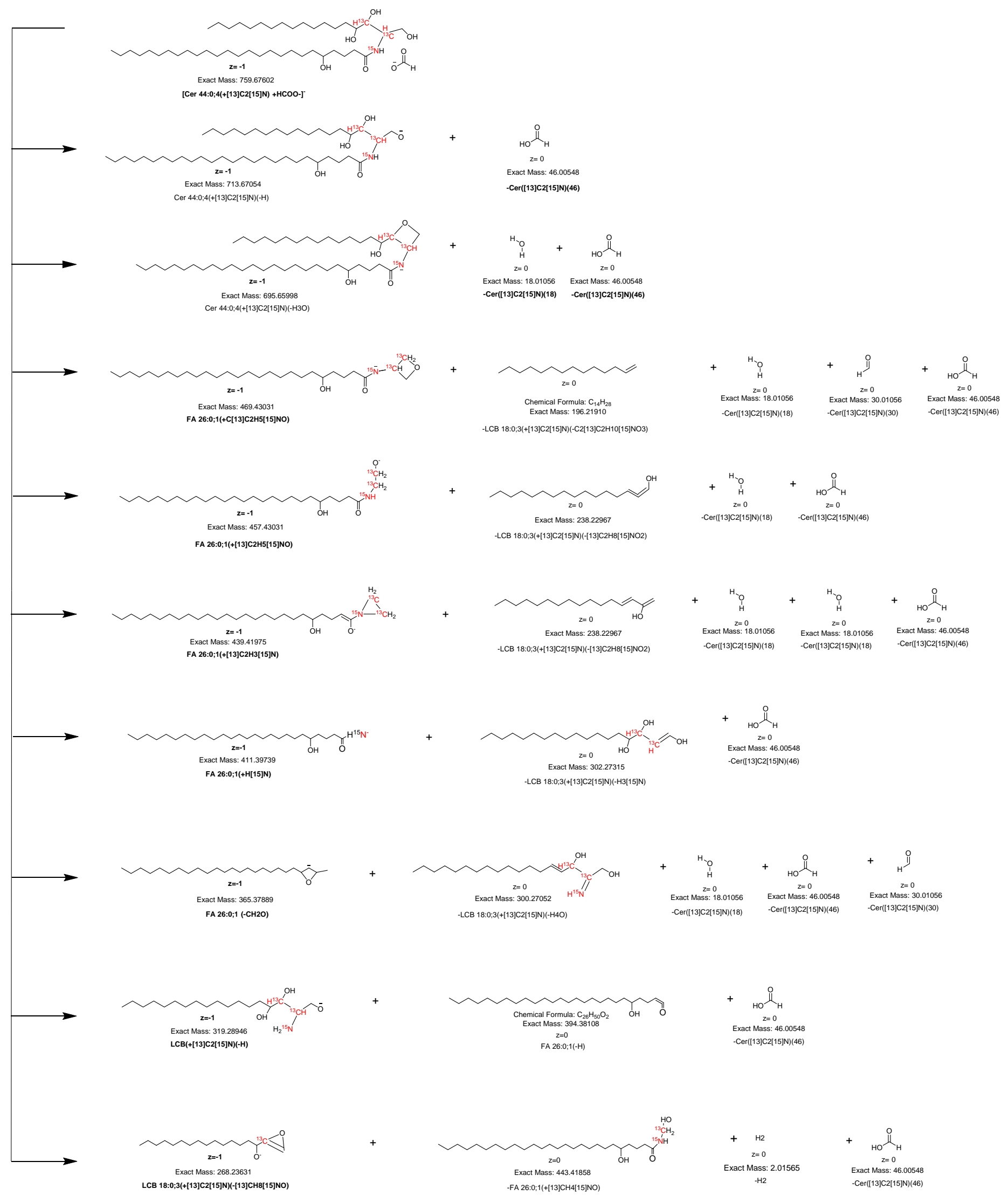

